\title{
The fourth International Standard for Human Urinary FSH and LH: specificities of LH seminal vesicle weight gain assays in the collaborative study differ between laboratories
}

\author{
P L Storring and R E Gaines Das \\ National Institute for Biological Standards and Control (WHO International Laboratory for Biological Standards), Blanche Lane, South Mimms, Potters Bar, \\ Hertfordshire EN6 3QG, UK \\ (Requests for offprints should be addressed to P L Storring)
}

\begin{abstract}
The fourth International Standard for Human Urinary FSH and LH (IS; in ampoules coded 98/704) was compared with the third International Standard for Urinary FSH and LH (IS 71/264) by 10 laboratories in nine countries, using FSH and $\mathrm{LH}$ in vivo bioassays.

Estimates of the FSH content of the IS by augmented ovarian weight gain assays were homogeneous within each laboratory and over all laboratories. The combined weighted geometric mean estimate of FSH content of the IS (with 95\% fiducial limits) in terms of IS $71 / 264$ was $71 \cdot 9(69 \cdot 0-74 \cdot 9)$ IU/ampoule.

Although estimates by seminal vesicle weight gain (SVW) assays of the relative LH activities of the IS and IS $71 / 264$ were homogeneous within laboratories, estimates were heterogeneous between laboratories. This indicated differences between the spectrum of $\mathrm{LH}$ isoforms in the IS and IS 71/264, which were obtained from different manufacturers, and differences between the specificities of SVW assays performed in different laboratories. The differences between the specificities of SVW assays appeared to be related to interactions among mean laboratory seminal vesicle weights, age and genetic strain
\end{abstract}

of rat. The finding of inter-laboratory differences in the specificities of SVW assays is of some significance, as this assay method has been generally adopted by Pharmacopoeias for the control of the LH content of therapeutic products. The combined unweighted geometric mean estimate of LH content of the IS (with 95\% fiducial limits) in terms of IS $71 / 264$ by SVW and ovarian ascorbate depletion assays was $70 \cdot 2(61 \cdot 7-80 \cdot 0) \mathrm{IU} /$ ampoule.

Estimates of the FSH and LH content of ampoules of the IS kept at increased temperatures suggested that the IS would be adequately stable under normal storage conditions.

On the basis of these results, the World Health Organization Expert Committee on Biological Standardization established the preparation in ampoules coded $98 / 704$ as the fourth International Standard for Human Urinary FSH and $\mathrm{LH}$, and assigned to the contents of each ampoule an activity of 72 International Units of urinary FSH and an activity of 70 International Units of urinary LH.

Journal of Endocrinology (2001) 171, 119-129

\section{Introduction}

Menotrophin and urinary and recombinant DNA-derived follicle-stimulating hormone (FSH) are widely used in the treatment of infertility in women, and sometimes also in men. The FSH and luteinizing hormone (LH) contents of these therapeutic products are controlled by in vivo bioassays. This is because the intrinsic heterogeneity of these gonadotrophins, and the degree of purity of the urinaryderived products, has until now precluded their control by physicochemical methods or by in vitro assays. Thus highly purified preparations of FSH and LH have been shown to differ in their isoform compositions (Zaidi et al. 1982a, b) and in their biological and immunological properties (Storring et al. 1981, 1982). Bioassays used to control these gonadotrophin therapeutic products have been calibrated in terms of the third International Standard for Urinary FSH and LH (in ampoules coded 71/264; IS 71/264), which was established by the World Health Organization (WHO) in 1993 (WHO Expert Committee on Biological Standardization (ECBS) 1994). The FSH content of menotrophin and of urinary FSH have also been estimated in terms of the first International Standard for Urofollitropin, which had been calibrated in terms of IS 71/264 and established in 1995 (Rose \& Gaines Das 1998, WHO ECBS 1998).

When stocks of IS 71/264 became depleted, the WHO ECBS requested the National Institute for Biological Standards and Control (NIBSC) to obtain and evaluate a replacement international standard (WHO ECBS 2000). 
A suitable preparation of menotrophin was therefore obtained and distributed into ampoules to become the fourth International Standard for Human Urinary FSH and LH (IS).

This paper describes the IS and its comparison with the IS 71/264 in an international collaborative study by FSH and $\mathrm{LH}$ in vivo bioassays. The study provided evidence that the IS was suitable to replace the IS $71 / 264$ as a standard for the bioassay of human urinary FSH and LH, and provided the calibration data used to assign the activities of the IS. The results of the study also showed unexpected between-laboratory differences in the specificities of seminal vesicle weight gain (SVW) assays, which are used to control the LH content of therapeutic products.

\section{Participants}

The ten laboratories from nine countries, which took part in the study, are listed below. Throughout this report each participant has been identified by a number between 1 and 10 , but these numbers do not relate to the order of listing which is alphabetical by country:

C Wolfenson, Instituto Massone SA, Arias 4431, 1430 Buenos Aires, Argentina; K Grant, Therapeutic Goods Administration, PO Box 100, Woden ACT 2606, Australia; S L Dalmora, Departamento de Farmácia Industrial, Universidade Federal de Santa Maria, 97.105.900-Santa Maria, RS, Brazil and P Bartolini, IPEN-CNEN, Universidade de São Paulo, Travessa R, 400-Cidade Universitária, 05508·900, São Paulo, Brazil; Li-gen Xu, Deming Qian, Hong-zheng Shen, Qun-li Liu \& Wei Leng, National Institute for the Control of Pharmaceutical and Biological Products, 2 Tiantan Xili, Beijing 100050, PR China; A Harazono \& M Ema, National Institute of Health Sciences, Osaka Branch, 1-1-43 Hoenzaka, Chuo-ku, Osaka, 540-0006, Japan; E Pithon, Laboratoires Serono SA, CH-1170 Aubonne, Switzerland and R Bussi \& G Zanolo, Istituto Ricerche Biomediche 'A Marxer', Via Ribes 1, 10010 Colleretto Giacosa, Italy; C Strijbos \& V Moffat, NV Organon, P O Box 20, 5340 BH Oss, The Netherlands; D Pelling, TNO BIBRA International Ltd, Woodmansterne Road, Carshalton, Surrey SM5 4DS, UK; P Gerson, R J Tiplady \& P L Storring, National Institute for Biological Standards and Control, Blanche Lane, South Mimms, Potters Bar, Herts EN6 3QG, UK; E A Raike, Qualtech Laboratories Inc., 104 Green Grove Road, Ocean, New Jersey NJ 07712, USA.

\section{Materials}

The second International Standard for Urinary FSH and LH (IS 71/223) and the third International Standard for Urinary FSH and LH (IS 71/264)

IS $71 / 223$ and IS $71 / 264$ consist of batches of ampoules coded $71 / 223$ and $71 / 264$, respectively, which contain an extract from the urine of post-menopausal women. Both of these standards were prepared from the same batch of master ampoules, using the same procedure as for the first International Standard for Human Urinary FSH and LH for Bioassay (in ampoules coded 70/45; IS 70/45), and both were included in the collaborative study of that standard (Storring et al. 1976). Subsequent supplementary studies confirmed the activity and stability of IS 71/223 (WHO ECBS 1989) and of IS 71/264 (WHO ECBS 1994).

In 1988, when stocks of IS 70/45 were becoming depleted, the WHO ECBS established the material in ampoules coded $71 / 223$ as the second International Standard for Urinary FSH and LH, and assigned to the contents of each ampoule the same activities as had been assigned to each ampoule of IS 70/45, namely an activity of 54 International Units of urinary FSH and 46 International Units of urinary LH (WHO ECBS 1989).

In 1993, when stocks of the second International Standard were becoming depleted, the WHO ECBS established the material in ampoules coded 71/264 as the third International Standard for Urinary FSH and LH, and assigned to the contents of each ampoule an activity of 54 International Units of urinary FSH and 46 International Units of urinary LH (WHO ECBS 1994).

The IS 71/223, which had been discontinued in 1993 with the establishment of IS $71 / 264$, was included in the study to supplement the available stocks of IS $71 / 264$ for the calibration of the IS.

\section{The fourth International Standard for Human Urinary FSH and $L H$ (IS)}

This consists of a batch of ampoules (coded 98/704) containing an extract from the urine of post-menopausal women.

Bulk FSH/LH This consisted of approximately $5 \cdot 8 \mathrm{~g}$ of menotrophin (Batch No. 61662697), extracted from the urine of post-menopausal women, and generously donated to WHO by the Instituto Massone, Buenos Aires, Argentina. It was stated to have an FSH specific activity of $86 \cdot 2 \mathrm{IU} / \mathrm{mg}$ by augmented ovarian weight gain assay and an LH specific activity of $82.7 \mathrm{IU} / \mathrm{mg}$ by SVW assay.

Distribution into ampoules The IS was prepared at NIBSC in November 1998. Some $5.8 \mathrm{~g}$ of the bulk menotrophin was dissolved in $6000 \mathrm{ml}$ of $0.5 \%(\mathrm{w} / \mathrm{v})$ lactose. The solution was passed through a $0.45 \mu \mathrm{m}$ membrane filter (Sartobran P, Sartorius), and distributed into ampoules as approximately $1.0 \mathrm{ml}$ aliquots. The solution of menotrophin was kept at $4{ }^{\circ} \mathrm{C}$ throughout. The ampoule contents were freeze-dried, secondarily desiccated and sealed under nitrogen (Campbell 1974, WHO ECBS 1978). The IS consisted of 5672 ampoules. The mean weight of filling solution in 113 weighed 
ampoules was found to be $1.006 \mathrm{~g}$, with a coefficient of variation of $0.13 \%$ and a range as a percentage of the mean of 1.09. Each ampoule of the IS contains about $0.967 \mathrm{mg}$ of the extract of human menopausal urine and $5 \mathrm{mg}$ of lactose.

Activity of ampoule contents Estimates of the FSH and LH activities of the IS and of the bulk menotrophin by FSH and LH in vivo bioassays at NIBSC suggested that there had been no significant loss of FSH or LH activity during the distribution of the bulk menotrophin into ampoules.

\section{Accelerated thermal degradation samples of the IS}

Ampoules of the IS which had been kept at $+20^{\circ} \mathrm{C}$, $+37^{\circ} \mathrm{C}$ or $+45^{\circ} \mathrm{C}$ for 320 days were coded, and were also included in the study.

\section{Methods}

\section{Design of the study}

Participants were asked to contribute in vivo bioassays which were, as far as possible, specific for FSH and LH. In particular they were asked, if possible, to contribute FSH estimates by the augmented ovarian weight gain (AOW) method (Steelman \& Pohley 1953), and LH estimates by the seminal vesicle weight gain (SVW) method (Van Hell et al. 1964) and the ovarian ascorbate depletion (OAAD) method (Parlow 1961). Participants were asked to assume an FSH potency of $70 \mathrm{IU} /$ ampoule and an LH potency of $60 \mathrm{IU} /$ ampoule for assays of the IS and its accelerated thermal degradation samples. Participants were asked to provide full results of their assays, including all raw data in addition to their own calculated estimates of potency.

\section{Statistical analysis}

For each assay for which the final body weights were reported, these variables were assessed by analysis of variance for any significant differences among treatment groups. As far as possible for each assay, four response metameters - namely organ weight, log of organ weight, organ weight relative to final body weight and log of organ weight relative to final body weight - were calculated and assessed for heterogeneity of variances and statistically significant outliers (using an in house program, SCAN, Gaines Das \& Rice 1985). Data for all assays using each of the available response metameters were also analysed as multiple parallel-line assays (see, for example, Finney 1978). The response metameter used for the reported analysis is that which, for the contributed assays, gave the more homogeneous variances and greatest precision (assessed as $\lambda=$ the ratio of the slope of the $\log$ dose-response metameter line to the pooled standard deviation of the responses). Estimates of potency for calibration of any preparation in terms of another have been calculated from direct analysis as a parallel-line assay of data for the preparation calibrated and the standard in terms of which it is calibrated, except where two thermally accelerated degradation samples were included with the IS in the same assay, when they were analysed as a multiple parallel-line assay. Estimates from assays for which the deviations from linearity or parallelism were significant $(P<0.01$ or $P<0.05)$ have been separately considered, and geometric mean potencies have been obtained both including and excluding these estimates. For each potency estimate, a statistical weight has been determined as the reciprocal of the variance of the $\log _{10}$ of the estimate.

Estimates of potency have been assessed for homogeneity using the $\chi^{2}$ test. Homogeneous estimates have been combined as weighted geometric means. Estimates that differed significantly from homogeneity $(P<0 \cdot 05)$ have been combined as unweighted geometric means, and the variance of these estimates has been calculated using the variance of the $\log$ estimates combined.

For the accelerated thermal degradation studies, predicted losses of activity at $-20{ }^{\circ} \mathrm{C}$ were calculated from degradation rates estimated assuming a linear relationship between log of degradation rate and reciprocal of absolute temperature (Jerne \& Perry 1956, Kirkwood 1977).

\section{Results}

\section{Assays contributed}

The 10 participants contributed results from a total of 56 assays: 29 AOW assays, 25 SVW assays and two OAAD assays. Eight of the 10 participants contributed final weights of animals together with organ weights (ovary for AOW assays or seminal vesicle for SVW assays), although laboratory 9 contributed body weights that could not be related unambiguously to the organ weights. The remaining two laboratories contributed organ weights only. As far as could be determined, assay designs were completely randomized, except in laboratory 3 , where a block design was used. The data from laboratory 3 have been analysed as if a completely randomized design had been used, as the relatively small effect attributable to blocks did not substantially affect the precision of estimates.

\section{Assessment of body weights and selection of response metameters}

In the majority of assays for which data were available (five participants), initial and final weights were significantly 
Table 1 Overall laboratory means of final weights of animals used for augmented ovarian weight gain assays, together with the coefficient of variation (CV) expressed as per cent of these. The response metameter used for the reported analysis is also given

\begin{tabular}{|c|c|c|c|c|c|c|}
\hline & $\begin{array}{l}\text { Rat strain } \\
\text { (age in days) }\end{array}$ & $\begin{array}{l}\text { Body } \\
\text { weight } \\
\text { (g) }\end{array}$ & $\begin{array}{l}\text { CV of } \\
\text { body } \\
\text { weight } \\
\text { (\%) }\end{array}$ & $\begin{array}{l}\text { Organ } \\
\text { weight } \\
\text { (mg) }\end{array}$ & $\begin{array}{l}\text { CV of } \\
\text { organ } \\
\text { weight } \\
(\%)\end{array}$ & Response metameter \\
\hline \multicolumn{7}{|c|}{ Laboratory } \\
\hline 1 & $\begin{array}{l}\mathrm{CH}-\mathrm{BB} \\
\text { Thom } \\
(20-23)\end{array}$ & 76 & 5 & 121 & 32 & Log ratio† \\
\hline 2 & $\begin{array}{l}\text { Wistar } \\
(24-30)\end{array}$ & 103 & 7 & 133 & 30 & Log organ weight \\
\hline 3 & $\begin{array}{l}\text { Lewis } \\
(21-28)\end{array}$ & NA & - & 111 & 32 & Log organ weight \\
\hline 4 & $\begin{array}{l}\text { Sprague- } \\
\text { Dawley } \\
(21-23)\end{array}$ & 51 & 8 & 93 & 39 & Log ratio† \\
\hline 5 & $\begin{array}{l}\text { Lewis } \\
(20-21)\end{array}$ & NA & - & 146 & 27 & Log organ weight \\
\hline 6 & $\begin{array}{l}\text { Wistar } \\
(23-26)\end{array}$ & 63 & 12 & 95 & 45 & Log ratio† \\
\hline 7 & $\begin{array}{l}\text { Wistar } \\
(19-22)\end{array}$ & 49 & 9 & 124 & 27 & Log ratio† \\
\hline 8 & $\begin{array}{l}\text { Sprague- } \\
\text { Dawley } \\
\text { (24) }\end{array}$ & 74 & 8 & 118 & 20 & Log ratio† \\
\hline 9 & $\begin{array}{l}\text { Sprague- } \\
\text { Dawley } \\
\text { Crl:CD } \\
(21-22)\end{array}$ & 67 & 6 & 96 & 32 & Log organ weight \\
\hline 10 & $\begin{array}{l}\text { Wistar } \\
(20-22)\end{array}$ & 54 & 9 & 90 & 35 & Log ratio† \\
\hline
\end{tabular}

NA, Not available.

†Denotes log of the ratio of organ weight to body weight.

correlated $(P>0 \cdot 01$, correlation coefficient generally about $0 \cdot 8-0 \cdot 9$ ), and the change in weight over the course of the assay showed no significant relations to the treatment (preparation or dose). The majority of participants who used body weights in their own analysis used the final weight, and further analysis has been carried out using final weights.

Body weights within each assay were homogeneous $(P>0.05)$ except in two assays. In one AOW assay of laboratory 1 , apparent heterogeneity resulted from a single outlying weight in one group, which was omitted from all further analysis. In one AOW assay of laboratory 2, variances differed significantly between different groups; there was no consistent pattern, and it has been assumed that this was an artefact of assignment of animals to groups.

Final body weights within each assay did not generally show any significant difference between treatment groups (analysis of variance, $P>0 \cdot 1$ ). Nevertheless, slopes of $\log$ dose-final body weight lines were calculated for each preparation in each assay in the study. The individual slopes were not significantly different from 0 . Considered over all SVW assays, the values of the slopes for IS $71 / 223$,
IS $71 / 264$ or the IS did not differ significantly $(P>0 \cdot 3)$ from 0 . Considered over all AOW assays, the values of the slopes for IS 71/223 and IS 71/264 also did not differ significantly from 0 . However, there was a slight overall tendency for the values of slopes for the IS to be negative $(14 / 21$ negative and $7 / 21$ positive; Student's $t$-test, $P \sim 0 \cdot 16)$. Whether this small difference would be reproducible and, if so, whether it reflects some characteristic of the IS or artefacts of assay design cannot be determined from these data.

Of the four response metameters, log transformation of either organ weight or ratio of organ weight to body weight gave markedly less heterogeneous groups than the untransformed variables in the majority of assays. For any one assay, values of $\lambda$ were generally not very different for the four response metameters (most values of $\lambda$ being within $10 \%$ of one another).

The overall laboratory means of final body weight and organ weight for the AOW and SVW assays, together with the response metameters used for the reported analysis are shown in Tables 1 and 2. The mean organ weights are broadly comparable between laboratories, because the 
Table 2 Overall laboratory means of final weights of animals used for seminal vesicle weight gain assays and of organ (seminal vesicle) weights, together with the coefficient of variation (CV) expressed as per cent of these. The response metameter used for the reported analysis is also given

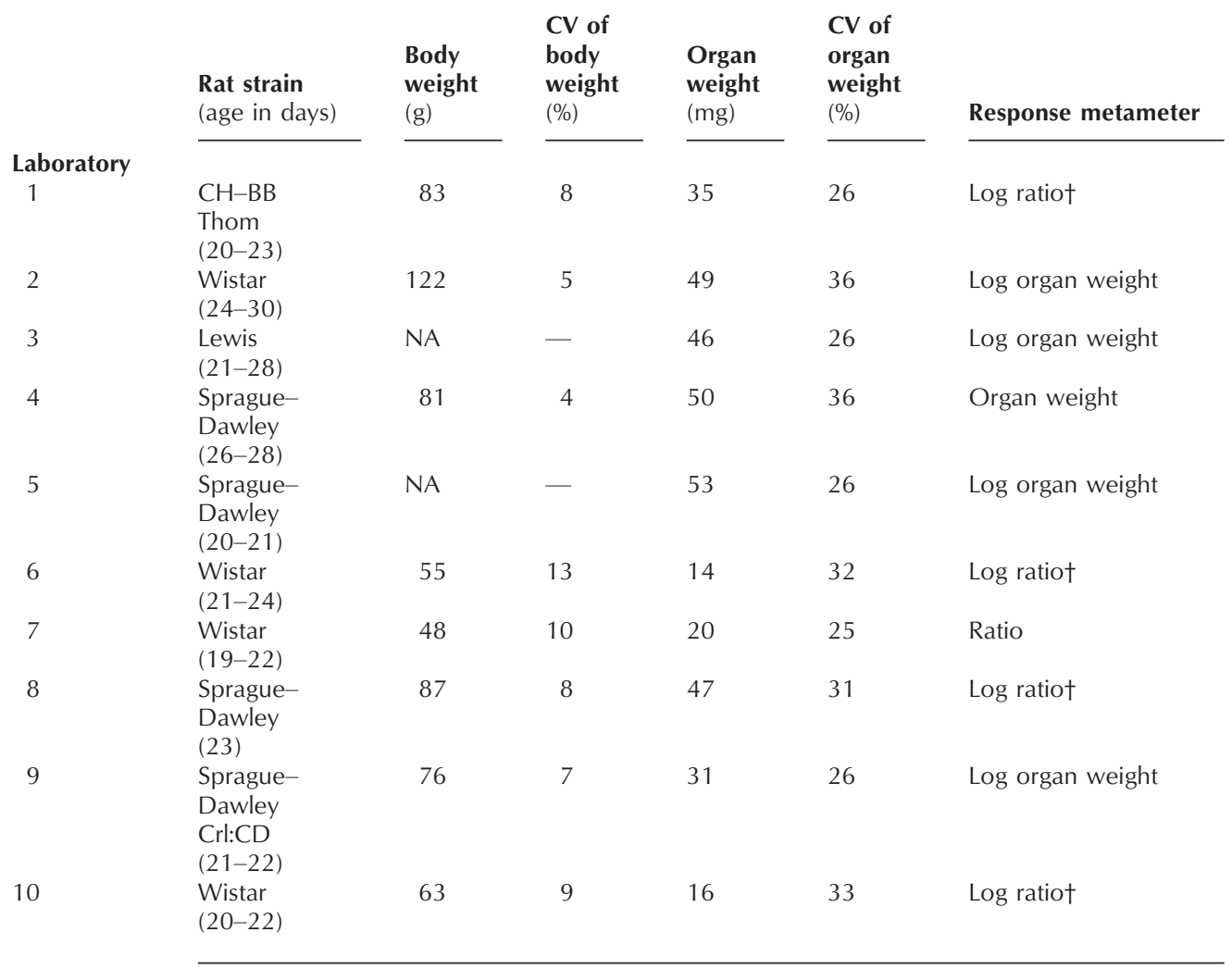

NA, Not available.

†Denotes log of the ratio of organ weight to body weight.

majority of assays comprised three doses of each preparation, with broadly similar ratios between largest and smallest doses and equal numbers of animals at each dose. For the FSH assays, the correlation of laboratory mean ovary weight and laboratory mean body weight was marginal $(r=0 \cdot 6, P \sim 0 \cdot 1)$ and there was no significant correlation of ovary weight and age; there was significant correlation $(r=0.8, P \sim 0.02)$ of laboratory mean body weights and age. The rats used for these FSH assays did not show any significant difference between strains for body or organ weight after allowance for age differences. For the LH assays, the correlation of laboratory mean seminal vesicle weight and laboratory mean body weight was significant $(r=0 \cdot 8, P \sim 0 \cdot 01)$, and the correlation of laboratory mean seminal vesicle weight and age was marginal $(r=0 \cdot 6, P \sim 0 \cdot 1)$; laboratory mean body weight and age were correlated $(r=0 \cdot 7, P \sim 0 \cdot 05)$. Among the animals used for these LH assays, the Sprague-Dawley rats were significantly heavier than the Wistar rats, with the difference more marked for the older rats, and the seminal vesicle weights of those groups of rats with an average age of less than 24 days were significantly $(P<0 \cdot 01)$ larger for Sprague-Dawley than for Wistar rats.

Data for all assays were assessed using the selected response metameter. Responses were homogeneous $(P>0.05)$ for all except eight of the 56 assays. These eight assays were further examined. In three of these assays there were either one or two markedly anomalous responses, which when deleted gave homogeneous groups of responses and were included as such for further analysis. In the remaining five assays there was no apparent reason for the observed heterogeneity. However, there was insufficient reason to reject these data, because these five assays neither contained any anomalous individual responses or groups of responses, nor gave any other evidence of invalidity. Such otherwise unexplained heterogeneity of responses can be an artefact of assay design.

Comparison of IS $71 / 223$ and IS $71 / 264$

FSH activity Comparisons of the FSH activities of these two preparations by AOW assays in two earlier 
Table 3 Estimates of the LH content of the second International Standard for Urinary FSH and LH (IS 71/223) in terms of the third International Standard for Urinary FSH and LH (IS 71/264). The number of estimates is given in parentheses

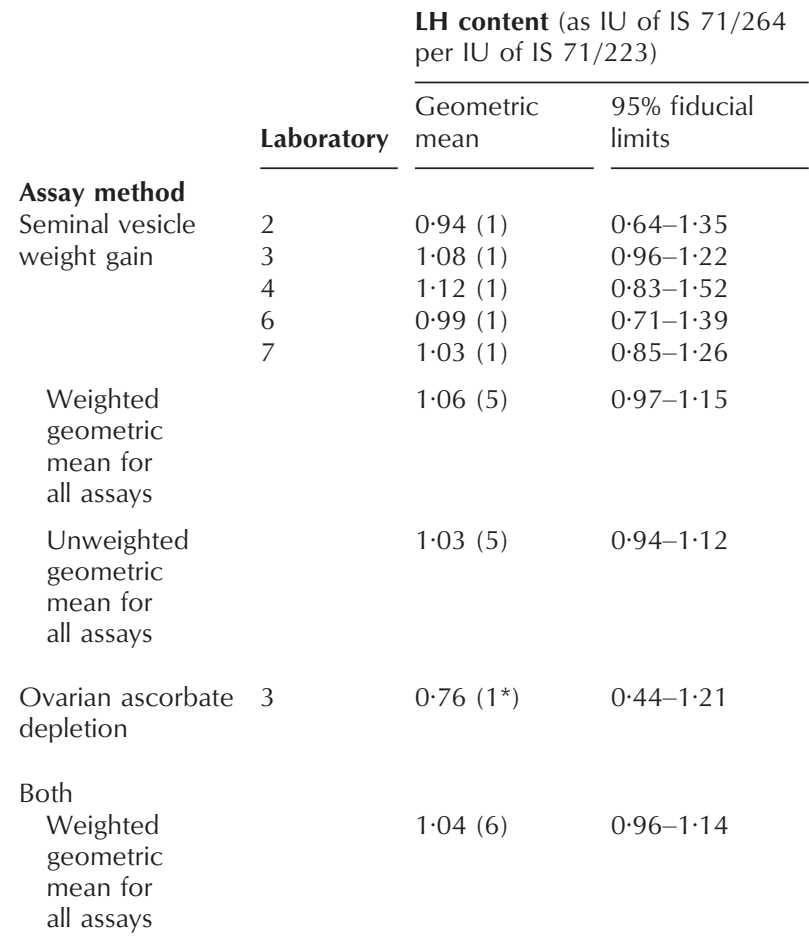

${ }^{*}$ This estimate is from an assay with significant $(P \sim 0 \cdot 02)$ deviation from parallelism.

collaborative studies had shown that their FSH potencies per ampoule, and hence per assigned IU, were equivalent (Storring et al. 1976, Rose \& Gaines Das 1998). In order to conserve stocks of IS $71 / 264$, calibration of the IS by AOW assays was therefore carried out in terms of IS $71 / 223$ and expressed in terms of IS 71/264.

LH activity Comparisons of the LH activities of these two preparations by in vivo bioassays in the earlier collaborative study had shown that their LH potencies per ampoule, and hence per assigned IU, were equivalent (Storring et al. 1976). However, this comparison was made some years ago, and therefore further direct comparisons of the LH activities of these two preparations have been made in this study in a limited number of assays, as shown in Table 3.

The estimates by SVW assay were homogeneous and gave a weighted geometric mean LH content for all assays (with $95 \%$ fiducial limits) of $1.06(0 \cdot 97-1 \cdot 15)$ IU of IS $71 / 264$ per IU of IS $71 / 223$ and an unweighted geometric mean LH content for all assays (with 95\% fiducial limits) of $1 \cdot 03(0 \cdot 94-1 \cdot 12)$ IU of IS $71 / 264$ per IU of IS $71 / 223$.
Table 4 Estimates of the FSH content of the fourth International Standard for Human Urinary FSH and LH in terms of the third International Standard for Urinary FSH and LH. The number of estimates is given in parentheses

FSH content (IU/ampoule)

\begin{tabular}{|c|c|}
\hline $\begin{array}{l}\text { Geometric } \\
\text { mean }\end{array}$ & $\begin{array}{l}95 \% \text { fiducial } \\
\text { limits }\end{array}$ \\
\hline $77 \cdot 1(2)$ & $66 \cdot 6-89 \cdot 3$ \\
\hline $68 \cdot 6(2)$ & $55 \cdot 1-85 \cdot 3$ \\
\hline $73 \cdot 0(2)$ & $67 \cdot 3-79 \cdot 2$ \\
\hline $65 \cdot 8(2)$ & $51 \cdot 4-84 \cdot 4$ \\
\hline $73.9(4)^{\mathrm{a}}$ & $67 \cdot 9-80 \cdot 4$ \\
\hline $59 \cdot 6(3)^{\mathrm{a}, \mathrm{b}}$ & $48 \cdot 4-73 \cdot 3$ \\
\hline $67 \cdot 7(2)$ & $58 \cdot 8-77 \cdot 9$ \\
\hline $74 \cdot 2(2)$ & $61 \cdot 6-89 \cdot 4$ \\
\hline $68 \cdot 7(2)$ & $58 \cdot 7-80 \cdot 4$ \\
\hline $74 \cdot 2(2)^{\mathrm{C}}$ & $64 \cdot 4-85 \cdot 6$ \\
\hline $71.9(23)$ & $69 \cdot 0-74 \cdot 9$ \\
\hline $71 \cdot 6(19)$ & $68 \cdot 5-74 \cdot 9$ \\
\hline $72 \cdot 3(25)$ & $69 \cdot 4-75 \cdot 2$ \\
\hline
\end{tabular}

ancluding one estimate from an assay with marginally significant $(0 \cdot 01<P<0 \cdot 05)$ deviations from linearity or parallelism.

bexcluding two estimates from assays with significant $(P<0 \cdot 01)$ deviations from parallelism.

Including two estimates from assays with marginally significant $(0 \cdot 01<P<0 \cdot 05)$ deviations from linearity or parallelism.

${ }^{\mathrm{d} E x c l u d i n g}$ estimates from four assays with marginally significant $(0 \cdot 01<P<0 \cdot 05)$ deviations from linearity or parallelism ${ }^{\mathrm{a}, \mathrm{c}}$.

encluding the two deleted estimates from assays with significant deviations from parallelism $(P<0 \cdot 01)^{\mathrm{b}}$.

These two preparations were also included in a single OAAD assay. In this comparison the OAAD assay showed non-parallelism of dose-response lines $(P \sim 0 \cdot 02)$. The reason for this is not known. However, this assay showed unexplained heterogeneity of responses and apparent outliers. Analysis appropriate to the block design showed significant interaction of blocks and regression. If the apparent statistical invalidity is ignored, the estimate obtained from this assay is not significantly different from 1 , and is not heterogeneous in combination with estimates from the SVW assays. Furthermore, if this value were included, the weighted geometric mean estimate of $\mathrm{LH}$ content (with 95\% fiducial limits) for all LH assays was $1.04(0 \cdot 96-1 \cdot 14)$ IU of IS $71 / 264$ per IU of IS $71 / 223$, which is very similar to the estimate given by the combination of SVW assays alone.

As the remaining stocks of IS 71/264 were insufficient to carry out the complete calibration of the IS, calibrations in terms of IS $71 / 223$ were used to supplement these data. For all these subsequent analyses, IS 71/223 and IS 71/264 have been treated interchangeably, and the results expressed in terms of IS $71 / 264$. Where the two preparations were included in the same assay, responses have been combined and treated as the responses of a single preparation, to give maximum precision for other 


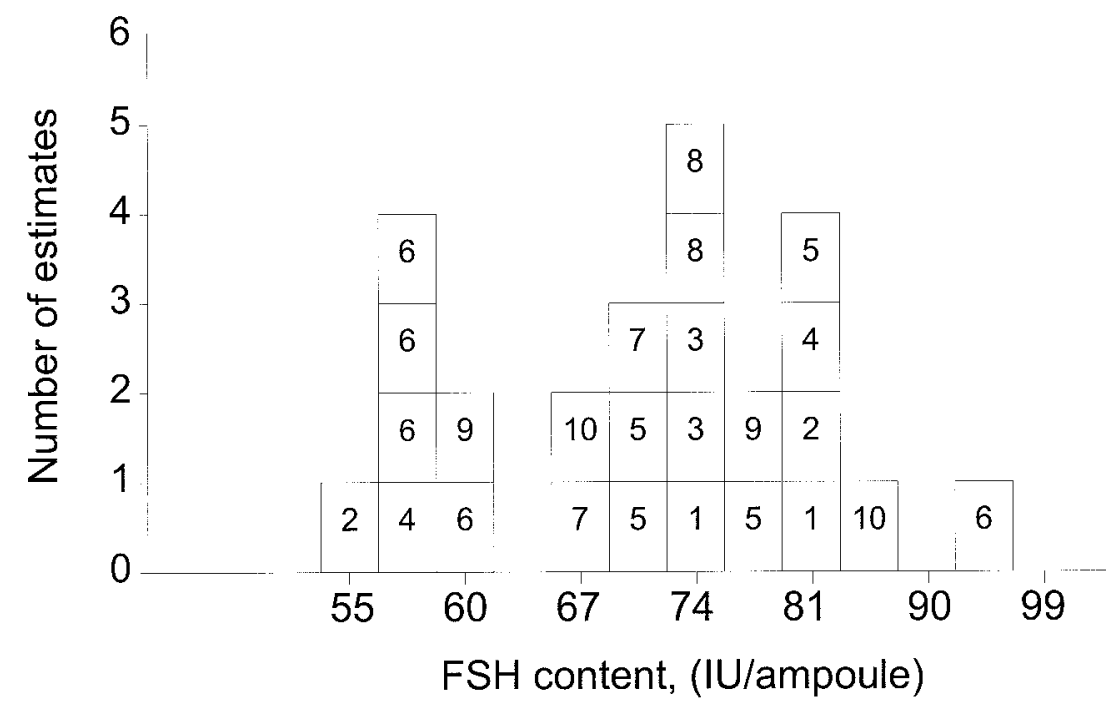

Figure 1 Frequency distribution of estimates of the FSH content of the fourth International Standard for Human Urinary FSH and LH in terms of the third International Standard for Urinary FSH and LH by augmented ovarian weight gain assays in different laboratories. Each box denotes the estimate from an individual assay, and the number in the box identifies the laboratory.

comparisons. All but one laboratory provided at least one SVW assay estimate in terms of IS $71 / 223$. All but two laboratories provided at least one SVW assay estimate in terms of IS $71 / 264$. The IS $71 / 223$ was used alone in 14 SVW assays, the IS 71/264 was used alone in four SVW assays, and both standards were used together in five SVW assays. One OAAD assay used the IS $71 / 223$ alone, and the other OAAD assay used both standards together.

\section{Calibration of the IS by FSH assays in terms of IS 71/264}

Table 4 and Fig. 1 present the results from this calibration. Two assays from laboratory 6 showed statistically significant deviations from parallelism $(P<0 \cdot 01)$. A further four assays (one each from laboratories 5 and 6 , and both assays from laboratory 10) showed marginal deviations from linearity or parallelism $(P \leqslant 0 \cdot 05)$. Although there were no significant deviations from parallelism in the majority of assays, there was a tendency for the slope of the log dose-response line for the IS to be larger than that for 71/264 (16 of 23 pairs of slopes, excluding the two assays with significant deviations from parallelism at the $1 \%$ level). The overall mean of slope differences was significantly larger than $0(P \sim 0.02$, Student's $t$-test).

Estimates of the FSH content of the IS were homogeneous within each laboratory and over all laboratories. The combined weighted geometric mean estimate of FSH content of the IS (with 95\% fiducial limits) was 71.9 (69.0-74.9) IU/ampoule (Table 4).
Calibration of the IS by LH assays in terms of IS 71/264

Results are presented in Table 5 and Fig. 2.

SVW assays Three SVW assays (one each from laboratories 1,3 and 4) showed marginal deviations from linearity or parallelism $(P \leqslant 0 \cdot 05)$. There was a slight tendency for the slope of the IS to be larger than that of IS $71 / 264$ (15 of 23 pairs of slopes). The overall mean of slope difference was marginally larger than $0(P \sim 0 \cdot 11$, Student's $t$-test).

All estimates by SVW assays were homogeneous within laboratories. However, estimates by SVW assays combined over all laboratories were highly significantly $(P<0 \cdot 0001)$ heterogeneous. The unweighted geometric mean of laboratory mean estimates of $\mathrm{LH}$ content of the IS (with 95\% fiducial limits) by SVW assays was $71 \cdot 8(62 \cdot 7-82 \cdot 2)$ IU/ ampoule (Table 5).

The modest difference between the slopes of the $\log$ dose-response lines of the IS and IS 71/264 in the SVW assays, not significant in the majority of assays, was not as great as that observed for the AOW assays, and seemed insufficient to account for the heterogeneity of estimates. However, the inter-laboratory heterogeneity of estimates in the presence of intra-laboratory homogeneity of estimates suggested differences between the specificities of SVW assay methods in different laboratories. In this context, it was noted that the larger estimates of potency appeared to come from assays in which larger overall seminal vesicle weights were observed (Fig. 3). The values 
Table 5 Estimates of the $\mathrm{LH}$ content of the fourth International Standard for Human Urinary FSH and LH in terms of the third International Standard for Urinary FSH and LH. The numbers in parentheses refer to the number of estimates in the case of laboratory means or the number of laboratory means in the case of means of laboratory means

\begin{tabular}{|c|c|c|c|}
\hline & & LH content & U/ampoule) \\
\hline & Laboratory & $\begin{array}{l}\text { Geometric } \\
\text { mean }\end{array}$ & $\begin{array}{l}95 \% \text { fiducial } \\
\text { limits }\end{array}$ \\
\hline Assay method & & & \\
\hline Seminal vesicle & 1 & $69 \cdot 8(2)^{*}$ & $60 \cdot 5-80 \cdot 6$ \\
\hline weight gain & 2 & $69 \cdot 0(3)$ & $59 \cdot 3-82 \cdot 4$ \\
\hline & 3 & $81 \cdot 0(2)^{*}$ & $74 \cdot 8-87 \cdot 7$ \\
\hline & 4 & $105 \cdot 1(2)^{*}$ & $88 \cdot 7-124 \cdot 6$ \\
\hline & 5 & $68 \cdot 5(2)$ & $60 \cdot 4-77 \cdot 7$ \\
\hline & 6 & $60 \cdot 5(4)$ & $52 \cdot 3-69 \cdot 9$ \\
\hline & 7 & $56 \cdot 9(2)$ & $50 \cdot 1-64 \cdot 7$ \\
\hline & 8 & $89 \cdot 4(2)$ & $71 \cdot 9-112 \cdot 2$ \\
\hline & 9 & $63 \cdot 6(2)$ & $56 \cdot 2-71 \cdot 9$ \\
\hline & 10 & $64 \cdot 8(2)$ & $55 \cdot 5-75 \cdot 5$ \\
\hline $\begin{array}{l}\text { Unweighted } \\
\text { geometric mean } \\
\text { of laboratory } \\
\text { mean estimates }\end{array}$ & & $71 \cdot 8(10)$ & $62 \cdot 7-82 \cdot 2$ \\
\hline $\begin{array}{l}\text { Unweighted } \\
\text { geometric mean } \\
\text { of laboratory } \\
\text { means excluding } \\
\text { estimates* }\end{array}$ & & $71.9(10)$ & $62 \cdot 3-83 \cdot 1$ \\
\hline $\begin{array}{l}\text { Ovarian ascorbate } \\
\text { depletion }\end{array}$ & 3 & $56 \cdot 7(2)$ & $45 \cdot 7-70 \cdot 4$ \\
\hline Both & & & \\
\hline $\begin{array}{l}\text { Unweighted } \\
\text { geometric mean } \\
\text { of laboratory } \\
\text { mean estimates }\end{array}$ & & $70 \cdot 2(11)$ & $61 \cdot 7-80 \cdot 0$ \\
\hline
\end{tabular}

*Including one estimate from an assay with marginally significant $(P \leqslant 0 \cdot 05)$ deviations from linearity or parallelism.

of the potency estimates by SVW assays were found to be significantly correlated with the laboratory mean seminal vesicle weight $(r=0.7, P \sim 0.02)$, and with age $(r=0.7$, $P \sim 0.03)$. It was noted that the two largest estimates of potency came from the two laboratories using SpragueDawley rats that were older than 22 days. Lewis rats, which were used in a single laboratory and which had an upper specified age range of 28 days, gave the third largest estimate of potency. These data were consistent with a strain-dependent effect on the specificity of SVW assays for rats older than 22 days. Although assay precision depends on many factors unique to each laboratory, precision of potency estimates also appeared to be greater in assays using Sprague-Dawley and Wistar rats that were younger than 22 days. This effect was not related to differences in the total number of animals used per assay, as shown by calculations of the statistical weight per animal.
The omission of laboratories 3, 4 and 8, which showed three of the four greatest mean laboratory seminal vesicle weights and the largest estimates of potency for the IS, gave $\log$ potency estimates for the IS in terms of $71 / 264$ which were homogeneous $(P \sim 0 \cdot 26)$, and which combined to give a weighted geometric mean of laboratory mean estimates of LH content of $64 \cdot 4 \quad(61 \cdot 1-67 \cdot 8)$ IU/ampoule.

OAAD assays The estimates from the two OAAD assays, which were carried out in laboratory 3, were consistent with estimates from the SVW assays with smaller mean organ weights, and when combined with all estimates by SVW assay gave an unweighted geometric mean of laboratory mean estimates of LH content (with $95 \%$ fiducial limits) of $70 \cdot 2 \quad(61 \cdot 7-80 \cdot 0)$ IU/ampoule (Table 5). Omitting the SVW estimates from laboratories 3, 4 and 8 gave a combined weighted geometric mean of (homogeneous) laboratory mean estimates of LH content (with 95\% fiducial limits) by SVW and OAAD assays of $63 \cdot 9(60 \cdot 8-67 \cdot 2) \mathrm{IU} /$ ampoule.

\section{Accelerated thermal degradation studies of the IS}

Laboratory mean estimates of the FSH and LH content of ampoules of the IS kept for 320 days at $20{ }^{\circ} \mathrm{C}, 37^{\circ} \mathrm{C}$ or $45^{\circ} \mathrm{C}$ in terms of ampoules of the IS kept at $-20^{\circ} \mathrm{C}$ are shown in Tables 6 and 7, respectively.

It was not possible for all samples to be tested in all laboratories. However, data from the limited number of laboratories testing several of the samples suggests that assays in the different laboratories may differently detect the apparent degradation of the IS.

AOW assays of laboratory 7 suggest that there has been, at most, a very slight loss of detectable FSH activity in any of the samples tested. In contrast, the AOW assays of laboratory 2 show a consistent significant loss of FSH activity with increasing temperature of storage except for an apparent increase in activity for the sample stored at $20{ }^{\circ} \mathrm{C}$. Based on the overall geometric means of laboratory means, the predicted loss of FSH activity at $-20{ }^{\circ} \mathrm{C}$ is less than $0 \cdot 1 \%$ per year.

The SVW assays of laboratory 7 , as in the case of its AOW assays, suggest that there has been, at most, a very slight loss of detectable LH activity in any of the samples tested. In contrast the SVW assays of laboratory 2, as in the case of its AOW assays, show a consistent significant loss of activity with increasing temperature of storage except for an apparent increase of activity for the sample stored at $20{ }^{\circ} \mathrm{C}$. The geometric means of laboratory means cannot be used to predict loss of $\mathrm{LH}$ activity, as there is no apparent change between samples stored at $37^{\circ} \mathrm{C}$ and $45^{\circ} \mathrm{C}$. However, if the mean of the sample stored at $37^{\circ} \mathrm{C}$, namely $87 \%$ of activity remaining, is used with the 'most common' estimate for the sample stored at $45^{\circ} \mathrm{C}$ 


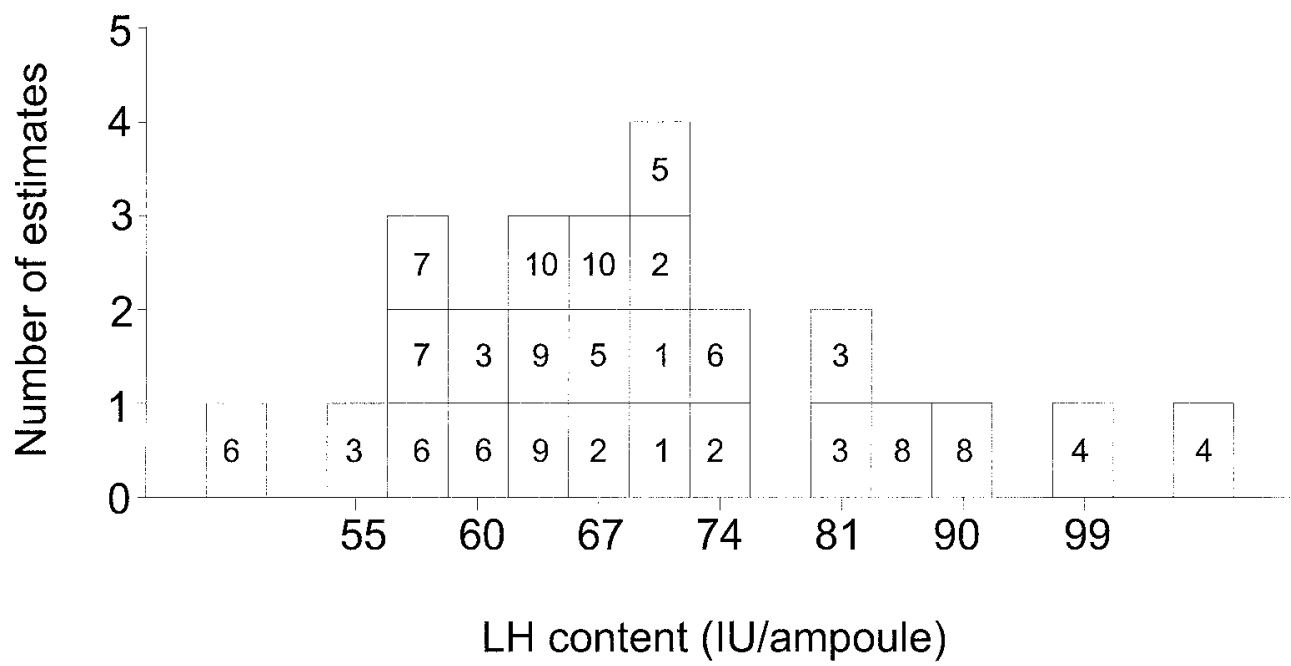

Figure 2 Frequency distribution of estimates of the LH content of the fourth International Standard for Human Urinary FSH and LH in terms of the third International Standard for Urinary FSH and LH by seminal vesicle weight gain assays (open boxes) and ovarian ascorbate depletion assays (shaded boxes) in different laboratories. Each box denotes the estimate from an individual assay, and the number in the box identifies the laboratory.

(78\% of activity remaining) the predicted loss of $\mathrm{LH}$ activity at $-20^{\circ} \mathrm{C}$ is also less than $0 \cdot 1 \%$ per year.

\section{Discussion}

\section{Comparison of IS and IS $71 / 264$}

The spectrum of FSH and $\mathrm{LH}$ isoforms present in the IS and in IS $71 / 264$ are likely to show some differences, because these hormone preparations are from different

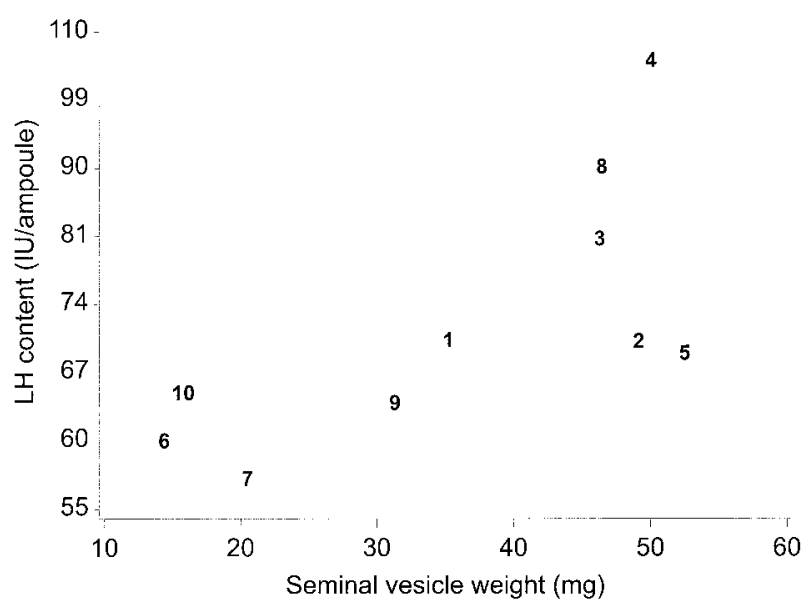

Figure 3 Comparison of laboratory mean estimates of the LH content of the fourth International Standard for Human Urinary $\mathrm{FSH}$ and $\mathrm{LH}$ by seminal vesicle weight gain assays in terms of the third International Standard for Urinary FSH and LH (as IU/ampoule) with laboratory mean seminal vesicle weights (as mg). Laboratories are identified by numbers. manufacturers. Such differences in FSH and LH isoform composition are probably the basis for the small, but consistent, differences observed between the slopes of the $\log$ dose-response lines for the IS and IS 71/264 in the

Table 6 Estimates of the FSH content of ampoules of the fourth International Standard for Human urinary FSH and LH (IS) kept for 320 days at $20^{\circ} \mathrm{C}, 37^{\circ} \mathrm{C}$ or $45^{\circ} \mathrm{C}$, in terms of ampoules of the IS kept at $-20^{\circ} \mathrm{C}$. The number of estimates is given in parentheses and the $95 \%$ fiducial limits are in square brackets

\section{Geometric mean FSH content}

(\% of that of the IS kept at $-20^{\circ} \mathrm{C}$ )

\begin{tabular}{|c|c|c|c|}
\hline & $\begin{array}{l}\text { IS kept at } 20^{\circ} \mathrm{C} \\
(\text { coded } \mathrm{C})\end{array}$ & $\begin{array}{l}\text { IS kept at } 37^{\circ} \mathrm{C} \\
(\operatorname{coded~A)}\end{array}$ & $\begin{array}{l}\text { IS kept at } 45^{\circ} \mathrm{C} \\
\text { (coded B) }\end{array}$ \\
\hline \multicolumn{4}{|l|}{ Laboratory } \\
\hline 1 & & $89(1)$ & $82(1)$ \\
\hline 2 & $126(2)$ & $82(3)$ & $59(2)$ \\
\hline 3 & & $77(1)$ & 67 (1) \\
\hline 4 & $146(1)$ & $44(1)$ & \\
\hline 6 & $86(1)$ & $93(1)$ & $53(1)$ \\
\hline 7 & $99(1)$ & $95(1)$ & $92(2)$ \\
\hline 10 & & & $60 *(2)$ \\
\hline $\begin{array}{l}\text { Geometric } \\
\text { mean of } \\
\text { laboratory } \\
\text { means }\end{array}$ & $112^{*}[77-163](4)$ & 80 [74-87] (6) & $68 *[54-84](6)$ \\
\hline $\begin{array}{l}\text { Geometric } \\
\text { mean of all } \\
\text { individual } \\
\text { estimates }\end{array}$ & $110(5)$ & $80(8)$ & $68^{*}(8)$ \\
\hline
\end{tabular}

*Unweighted geometric mean of heterogeneous estimates. 
Table 7 Estimates of the $\mathrm{LH}$ content of ampoules of the fourth International Standard for Human Urinary FSH and $\mathrm{LH}$ (IS) kept for 320 days at $20^{\circ} \mathrm{C}, 37^{\circ} \mathrm{C}$ or $45^{\circ} \mathrm{C}$, in terms of ampoules of the IS kept at $-20^{\circ} \mathrm{C}$. The number of estimates is given in parentheses and the $95 \%$ fiducial limits are in square brackets

\begin{tabular}{|c|c|c|c|c|}
\hline & & $\begin{array}{l}\text { Geometric mean } \\
\text { (\% of that of the IS }\end{array}$ & $\begin{array}{l}\text { content } \\
\text { ept at }-20^{\circ} \mathrm{C} \text { ) }\end{array}$ & \\
\hline & Laboratory & $\begin{array}{l}\text { IS kept at } 20^{\circ} \mathrm{C} \\
\text { (coded } \mathrm{C} \text { ) }\end{array}$ & $\begin{array}{l}\text { IS kept at } 37^{\circ} \mathrm{C} \\
(\operatorname{coded} \mathrm{A})\end{array}$ & $\begin{array}{l}\text { IS kept at } 45^{\circ} \mathrm{C} \\
\text { (coded } \mathrm{B} \text { ) }\end{array}$ \\
\hline Assay method & & & & \\
\hline Seminal vesicle & 1 & $92(1)$ & - & $78(1)$ \\
\hline weight gain & 2 & $116(2)$ & $83(2)$ & $79(1)$ \\
\hline & 3 & - & $91(1)$ & - \\
\hline & 4 & $91(1)$ & - & - \\
\hline & 6 & - & - & $77(1)$ \\
\hline & 7 & $100(2)$ & - & $99(1)$ \\
\hline & 10 & - & - & $78^{*}(2)$ \\
\hline wgmlm & - & 100 [91-110] (4) & 87 [79-97] (2) & 86 [76-97] (5) \\
\hline $\begin{array}{l}\text { Ovarian ascorbate } \\
\text { depletion }\end{array}$ & 3 & - & - & $83(1)$ \\
\hline Both & & & & \\
\hline wgmlm & - & - & - & 85 [76-95] (6) \\
\hline
\end{tabular}

AOW and SVW assays contributed to this collaborative study. Furthermore, differences in LH isoform composition between the IS and IS 71/264 are probably also the basis for the highly significant between-laboratory heterogeneity of estimates by SVW assay for the LH content of the IS in terms of IS 71/264. In contrast, estimates by SVW assay of the relative LH potencies of IS $71 / 223$ and IS $71 / 264$, which originated from the same hormone preparation, were homogeneous between laboratories.

\section{Selectivity of SVW assays}

Although estimates by SVW assays of the relative LH activities of the IS and IS 71/264 were homogeneous within laboratories, estimates were heterogeneous between laboratories. This indicated differences between the specificities of SVW assay methods in different laboratories. These inter-laboratory differences in the selectivity of SVW assays in detecting the differences between the spectrum of LH isoforms in the IS and IS $71 / 264$ appeared to be related to the size of the seminal vesicles and age of the assay animals, and hence perhaps the degree of maturity of their LH target cells. Thus there was a significant correlation between the value of the $\mathrm{LH}$ potency estimate for the IS in terms of IS 71/264 obtained in a laboratory and both the overall mean seminal vesicle weight and age of the assay animals in that laboratory.
The limited data in this study are consistent with a strain-dependent effect among older rats.

In contrast, for the AOW assays, in which organ weights did not differ greatly between laboratories, the correlation between organ weight and the FSH potency estimate was not significant (correlation coefficient $r=0 \cdot 38, P \sim 0 \cdot 3)$.

We are not aware of any previous report in the literature of such relationships between mean assay seminal vesicle weights, age or rat strain and the selectivity of SVW assays. The assay as originally described by Van Hell et al. (1964) used pre-pubertal rats of unspecified strain with ages in the range from 21 to 28 days. (The age range of rats for the SVW assay described in the British Pharmacopoeia (2000) and European Pharmacopoeia (1997) is 19-28 days, and for that described in the United States Pharmacopoeia (2000) is 20-21 days. The strains of rat to be used for the SVW assays described in these three pharmacopoeias are not specified.) The earlier generation of LH assay in which weight gain of male accessory organs was used as response, namely the ventral prostate weight gain assay (Greep et al. 1941), used 21-22-day-old hypophysectomized rats of unspecified strain, in which the maturity and selectivity of LH target cells may have been more precisely defined. This finding of inter-laboratory differences in the specificities of SVW assays is of some significance because, as indicated above, this assay method has been generally adopted by 
Pharmacopoeias for the control of the LH content of therapeutic products.

\section{Suitability of the IS for the standardization of FSH and LH}

The participants in the collaborative study agreed that the IS appears to be suitable to replace the IS $71 / 264$ as the international standard for urinary FSH and urinary LH. Thus the IS was found (a) to contain urinary FSH and urinary LH with specific FSH and LH activities of the same order as those of the IS $71 / 264$, as estimated by in vivo bioassay methods which are specific for FSH and $\mathrm{LH}$, and which are specified for the estimation of urinary FSH and LH in pharmacopoeial monographs; and (b) to be adequately stable, on the basis of accelerated thermal degradation studies, when stored under normal conditions, at $-20{ }^{\circ} \mathrm{C}$ in the dark.

\section{Establishment of the fourth International Standard for Human Urinary FSH and LH}

On the basis of the results of the collaborative study, and with the agreement of the participants, the WHO ECBS established the preparation in ampoules coded 98/704 as the fourth International Standard for Human Urinary FSH and $\mathrm{LH}$ and assigned to the contents of each ampoule an activity of 72 International Units of urinary FSH and an activity of 70 International Units of urinary LH (WHO ECBS, 51st Report).

\section{Acknowledgements}

Grateful acknowledgements are due to the following: the participants in the study; the Instituto Massone (through the good offices of $\mathrm{Mr} \mathrm{R}$ Massone) and Serono for providing bulk menotrophin preparations; to Mr P Gerson and Mr R J Tiplady for preliminary bioassays; and to Dr P Dawson for ampouling.

\section{References}

British Pharmacopoeia 2000. London: The Stationery Office.

Campbell PJ 1974 International biological standards and reference preparations. II. Procedures used for the production of biological standards and reference preparations. Journal of Biological Standardization 2 259-267.

European Pharmacopoeia 1997. Strasbourg: Council of Europe.

Finney DJ 1978 Statistical Method in Biological Assay, edn 3. London: Griffin.

Gaines Das RE \& Rice LR 1985 SCAN, an exploratory program for preliminary analysis of bioassay and immunoassay data. Computer Methods and Programs in Biomedicine 21 25-33.
Greep RO, van Dyke HB \& Chow BF 1941 Use of anterior lobe of prostate gland in the assay of metakentrin. Proceedings of the Society for Experimental Biology and Medicine 46 644-649.

Jerne NK \& Perry WLM 1956 The stability of biological standards. Bulletin of the World Health Organization 14 167-182.

Kirkwood TBL 1977 Predicting the stability of biological standards and products. Biometrics 33 736-742.

Parlow AF 1961 Bioassay of pituitary luteinizing hormone by depletion of ovarian ascorbic acid. In Human Pituitary Gonadotropins, pp 300-310. Ed. A Albert. Springfield, Illinois: Charles C Thomas.

Rose MP \& Gaines Das RE 1998 Characterisation, calibration and comparison by international collaborative study of international standards for the calibration of therapeutic preparations of FSH. Journal of Endocrinology 158 97-114.

Steelman SL \& Pohley FM 1953 Assay of the follicle-stimulating hormone based on the augmentation with human chorionic gonadotropin. Endocrinology 53 604-616.

Storring PL, Dixon H \& Bangham DR 1976 The first international standard for human urinary FSH and for human urinary LH (ICSH), for bioassay. Acta Endocrinologica 83 700-710.

Storring PL, Zaidi AA, Mistry YG, Fröysa B, Stenning BE \& Diczfalusy E 1981 A comparison of preparations of highly purified human pituitary follicle-stimulating hormone: differences in the follicle-stimulating hormone potencies as determined by in-vivo bioassay, in-vitro bioassay and immunoassay. Journal of Endocrinology $91353-362$.

Storring PL, Zaidi AA, Mistry YG, Lindberg M, Stenning BE \& Diczfalusy E 1982 A comparison of preparations of highly purified human pituitary luteinizing hormone: differences in the luteinizing hormone potencies as determined by in-vivo bioassays, in-vitro bioassay and immunoassay. Acta Endocrinologica 101 339-347.

United States Pharmacopeia 2000. Rockville, Maryland, USA: United States Pharmacopeial Convention Inc.

Van Hell H, Matthijsen R \& Overbeek GA 1964 Effects of human menopausal gonadotrophin preparations in different bioassay methods. Acta Endocrinologica 47 409-418.

WHO Expert Committee on Biological Standardization 1978 29th Report. WHO Technical Report Series No. 626.

WHO Expert Committee on Biological Standardization 1989 39th Report. WHO Technical Report Series No. 786.

WHO Expert Committee on Biological Standardization 1994 44th Report. WHO Technical Report Series No. 848.

WHO Expert Committee on Biological Standardization 1998 46th Report. WHO Technical Report Series No. 872.

WHO Expert Committee on Biological Standardization 2000 49th Report. WHO Technical Report Series No. 897.

WHO Expert Committee on Biological Standardization 51st Report. WHO Technical Report Series (In Press).

Zaidi AA, Fröysa B \& Diczfalusy E 1982a Biological and immunological properties of different molecular species of human follicle-stimulating hormone: electrofocusing profiles of eight highly purified preparations. Journal of Endocrinology 92 195-204.

Zaidi AA, Qazi MH \& Diczfalusy E $1982 b$ Molecular composition of human luteinizing hormone: biological and immunological profiles of highly purified preparations after electrofocusing. Journal of Endocrinology 94 29-36.

Received in final form 22 May 2001 Accepted 4 June 2001 